\title{
Oesophageal Carcinoma in a Young Adult Somali Patient: A Case Report with Brief Literature Review
}

\author{
Mohamed Abdulkadir Hassan Kadle*, Osman Mohamud Dufle \\ Dufle Specialist Hospital, Mogadishu, Somalia \\ Email: ${ }^{\text {Kadlesom@gmail.com }}$
}

Received 18 May 2015; accepted 20 June 2015; published 23 June 2015

Copyright (C) 2015 by authors and Scientific Research Publishing Inc.

This work is licensed under the Creative Commons Attribution International License (CC BY). http://creativecommons.org/licenses/by/4.0/ cC) (7) Open Access

\begin{abstract}
The present case report describes a 30 years old Somali male diagnosed to have a well-differentiated squamous cell carcinoma of the oesophagus. We report this case with a brief literature review because of its infrequency in the younger age group.
\end{abstract}

Keywords

Oesophageal Cancer, Squamous Cell Carcinoma, Adenocarcinoma, Young Age, Somalia

\section{Introduction}

The oesophageal cancer is one of the cancers having nastiest prognosis. It occurs mostly in individuals over fifty years old. A few cases of oesophageal carcinoma in younger age groups have been reported in the world. This cancer occurs histologically in two forms, Squamous Cell Carcinomas (SCC) affecting the stratified squamous epithelial lining the oesophagus and adenocarcinomas affecting the oesophageal glands [1]-[3]. There is little information concerning oesophageal carcinoma in the country. Oesophageal resections have been performed in four patients with this tumor at Medina Hospital, Mogadishu, Somalia. Two patients were died after the operation due to mediastinal fistulae and two were survived [4]. Due to scarceness of researches and rarity of this cancer in younger age groups, this case report contributes a recent data base on human carcinomas in the country.

\section{Case Report}

A 30 years old male presented to our hospital (Dufle Specialist Hospital, Mogadishu, Somalia) with dysphagia

\footnotetext{
${ }^{*}$ Corresponding author.
}

How to cite this paper: Kadle, M.A.H. and Dufle, O.M. (2015) Oesophageal Carcinoma in a Young Adult Somali Patient: A Case Report with Brief Literature Review. Case Reports in Clinical Medicine, 4, 241-243. 
as a chief complaint progressively increasing over a two-month period. Initially, he had difficulty in swallowing solid foods with feeling of food trapping in the retrosternal region. The severity of his dysphagia was progressive; semi-solids and even liquids were difficult to be swallowed. Since the start of this problem, his weight was going down. Other gastrointestinal complaints (chest pain, heart burn or nausea) were absent. He was neither a cigarette smoker nor had history of ingestion of any corrosive substances in his life. However, he reported consuming chewing tobacco and drinking hot tea which are reported to be the associated risk factors for this cancer, B. Ganesh et al. [5]. Physical examination on admission showed a thin and apprehensive patient. The blood pressure was 120/80 mm Hg and pulse 74/minute. No signs of icterus, cervical lymphadenopathy, hyperkeratosis of palms and soles were detected. Liver was impalpable and ascites was negative.

All laboratory examinations including liver and kidney function tests were normal.

The patient ordered to do a chest X-ray. A barium swallow revealed mucosal irregularity at the middle part of the oesophagus with shouldering of the barium filled oesophagus (Figure 1).

Endoscopy and chest Computed Tomography Scan (CT scan) which were not available at our hospital were ordered for further evaluation. Gastroscopic examination revealed a tumour in the middle part of the oesophagus obstructing the oesophageal lumen. Biopsies from the diseased portion were taken and revealed a well-differentiated squamous cell carcinoma (SCC). An Oesophageal stent was inserted. CT scan of the chest and abdomen revealed no evidence of metastases but showed a stent in the upper and middle part of the oesophagus with no evidence narrowing distal to it. The above procedures were carried out at St Mary's Mission hospital, Plaza Imaging Solutions and Cancer Care Centre in Nairobi, Kenya.

The patient was elected to undergo chemotherapy. After one month of his return to Somalia, he unfortunately died.

\section{Discussion}

Oesophageal carcinoma represents a serious tumour disease worldwide. In most cases, it is characterised by a fatal prognosis. Worldwide, it ranks the sixth most frequent cause of cancer death. It occurs most frequently in the age groups over fifty years and found to be more in males than in females [6] [7]. Histologically, oesophageal carcinoma occurs in two types; Squamous Cell Carcinoma (SCC) and adenocarcinoma. The first type occurs most frequently than the second type. A well-differentiated SCC was shown in our patient. About $60 \%$ of the SCC occurs in the middle, 30\% in the distal part and 10\% in the proximal part of the oesophagus [1] [2] [7]. Oesophageal carcinoma is predominantly produced by the environmental factors requiring a long latent period which leads to the rarity of this cancer in young ages [8]. In our patient the associated risk factors for oesophageal carcinoma were chewing tobacco and drinking hot tea for a long time. Oesophagram, Esophagogastroduodenoscopy (EGD), Endoscopic ultrasound, Biopsy, CT scan, Magnetic resonance imaging (MRI), Positron

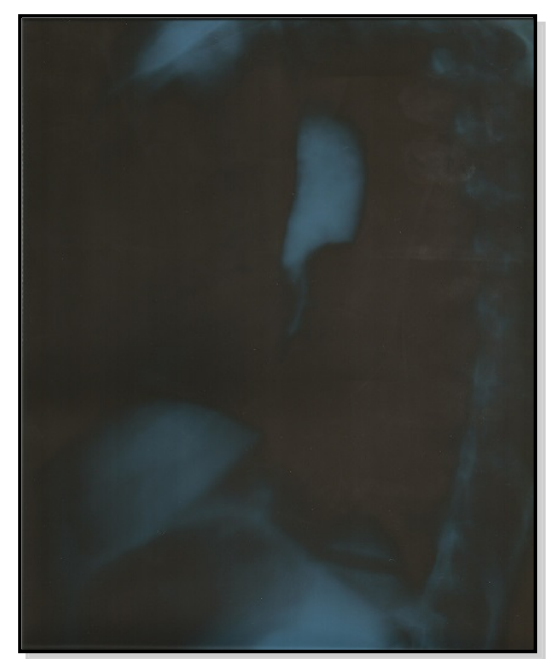

Figure 1. Barium swallow shows abrupt narrowing at the middle part of the esophagus with mucosal irregularity. 
emission tomography (PET) scan and Molecular testing of the tumour are the most diagnostic tests used to diagnose oesophageal cancers. The management of the disease and its outcome depends on the stage of the cancer. Surgery, radiation and chemotherapy are the main approaches for the treatment of oesophageal cancers. However, surgery is the mainstay of treatment for all stages of the disease. Our patient was treated with chemotherapy but after one month of his return to the country, he unfortunately died. Avoidance of the risk factors of this disease and early detection of precancerous lesions, especially of Barrett's oesophagus, will help to reduce its occurrence [7]-[11].

\section{Conclusion and Recommendations}

It can be concluded that in our country, oesophageal carcinoma is likely to occur in younger age group when associated risk factors for the tumour are present. This case report recommends an early diagnosis of oesophageal carcinoma in young ages and the need for extensive researches in the whole country. Establishments of a well-equipped gastrointestinal endoscopy and cancer care centres in the country along with a well-trained professionals are recommended.

\section{Acknowledgements}

We are thankful to Ahmed A. Hassan for helping us during preparation of the manuscript.

\section{References}

[1] Kedar, A., Dilip, L., Mitesh, K. and Anand, B. (2014) A Rare Case Report of Carcinoma Esophagus in Young Adult. International Journal of Pharma Research and Health Sciences, 2, 215-218.

[2] Semnani, Sh., Abdollahi, N., Kalavi, Kh. and Azarhoosh, R. (2005) Esophageal Cancer in an Iranian 20 Years Old Young Male-A Case Report. International Journal of Cancer Research, 1, 57-59. http://dx.doi.org/10.3923/ijcr.2005.57.59

[3] Zhang, Y. (2013) Epidemiology of Esophagealcancer. World Journal of Gastroenterology, 19, 5598-5606. http://dx.doi.org/10.3748/wjg.v19.i34.5598

[4] Hassan, M.Y., Elmi, A.M. and Baldan, M. (2004) Experience of Thoracic Surgery Performed under Difficult Conditions in Somalia. East and Central African Journal of Surgery, 9, 94-96.

[5] Ganesh, B., Talole, S.D. and Dikshit, R. (2009) Tobacco, Alcohol and Tea Drinking as Risk Factors for Esophageal Cancer: A Case-Control Study from Mumbai, India. The International Journal of Cancer Epidemiology, Detection, and Prevention, 33, 431-434. http://dx.doi.org/10.1016/j.canep.2009.09.002

[6] Pisani, P., Parkin, D.M., Bray, F. and Ferlay, J. (1999) Estimates of the Worldwide Mortality from 25 Cancers in 1990. International Journal of Cancer, 83, 18-29. http://dx.doi.org/10.1002/(SICI)1097-0215(19990924)83:1<18::AID-IJC5>3.0.CO;2-M

[7] Kollarova, H., Machova, L., Horakova, D., Janoutova, G. and Janout, V. (2007) Epidemiology of Esophageal Cancer-An Overview Article. Biomedical Papers of the Medical Faculty of the University Palacký, Olomouc, Czechoslovakia, 151, 17-28. http://dx.doi.org/10.5507/bp.2007.003

[8] Hedawoo, J.B., Nagdeve, N.G. and Sarve, G.N. (2010) Squamous Cell Carcinoma of Esophagus in a 15-Year-Old Boy. Journal of Indian Association of Pediatric Surgeons, 15, 59-61. http://dx.doi.org/10.4103/0971-9261.70641

[9] http://www.cancer.net/cancer-types/esophageal-cancer

[10] Lin, S.H. and Chang, J.Y. (2010) Esophageal Cancer: Diagnosis and Management. Chinese Journal of Cancer, 29, 843-854. http://dx.doi.org/10.5732/cjc.010.10151

[11] Montgomery, E.A., et al. (2014) Oesophageal Cancer. In: Stewart, B.W. and Wild, C.P., Eds., World Cancer Report 2014, World Health Organization, 528-543. 